\title{
A NEW VIEW OF THE VESALIAN LANDSCAPE
}

\author{
by
}

\section{G. S. T. CAVANAGH*}

OF all medical books, the De humani corporis fabrica of Andreas Vesalius in its two folio editions of 1543 and 1555 has probably been the object of most study and attention. Even today when its difficult late Latin and the absence of a full English translation make it inaccessible to all but a small number of scholars, its woodcut illustrations are still familiar to any one with the slightest interest in medical history. The larger illustrations have been pored over by art historians as well as historians of medicine, but there has been a marked lack of unanimity on many points including the identity of the artist or artists. Though there are more than two hundred illustrations in the book, most of the attention from the artistic side has been focused on the fourteen full-page figures of "muscle-men" in the second book. One distinguishing feature of these which is not found elsewhere in Vesalius or his contemporary anatomists is the use of parts of a detailed and convincing landscape as background to the figures. Whereas bits of rock and vegetation are drawn in as decoration for the skeletal figures, the muscle-men stand against hills and valleys, villages and trees, and even a Roman ruin. The total effect is one of actuality and close observation which is not characteristic of earlier anatomical books.

At least since 1903,1 it has been recognized that the backgrounds of a number of muscle-men can be linked together to form a panoramic landscape, or more probably two separate landscapes. Cushing ${ }^{2}$ reproduced the anterior and posterior series of muscle figures arranged to show this feature. The curious thing is that when assembled this way in an order dictated by the landscape, the figures appear roughly in the reverse of the expected order, with the most dissected man at the beginning (left) of each series and the whole écorche on the right. Besides being contrary to custom and logic, this is the opposite of the order in which they occur in the published Fabrica itself.

This peculiarity was remarked on by Wiegand, ${ }^{3}$ who disposed of it by saying that whereas our twentieth-century minds expect a consistent presentation, the men of the sixteenth century were not so trammelled, and by $\mathbf{O}^{\prime}$ Malley, ${ }^{4}$ who used the

${ }^{*}$ G. S. T. Cavanagh, BA, BLS, Curator, Trent Collection, Duke University Medical Center Library, Durham, NC 27710, USA.

\footnotetext{
'E. Jackschath, 'Zu den anatomischen Abbildung des Vesals', Janus, 1904, 9: 239.

${ }^{2}$ Harvey Cushing, A bio-bibliography of Andreas Vesalius, New York, Schuman, 1943, Fig. 59.

${ }^{3}$ Willy Wiegand, 'Marginal notes by the printer of the Icones', in Three Vesalian essays to accompany the 'Icones anatomicae', New York, Macmillan, 1952, pp. 25-62, see pp. 40-41.

'C. D. O’Malley, Andreas Vesalius of Brussels, 1514-1564. Berkeley and Los Angeles, University of California Press, 1964, p. 128.
} 
1 Nu

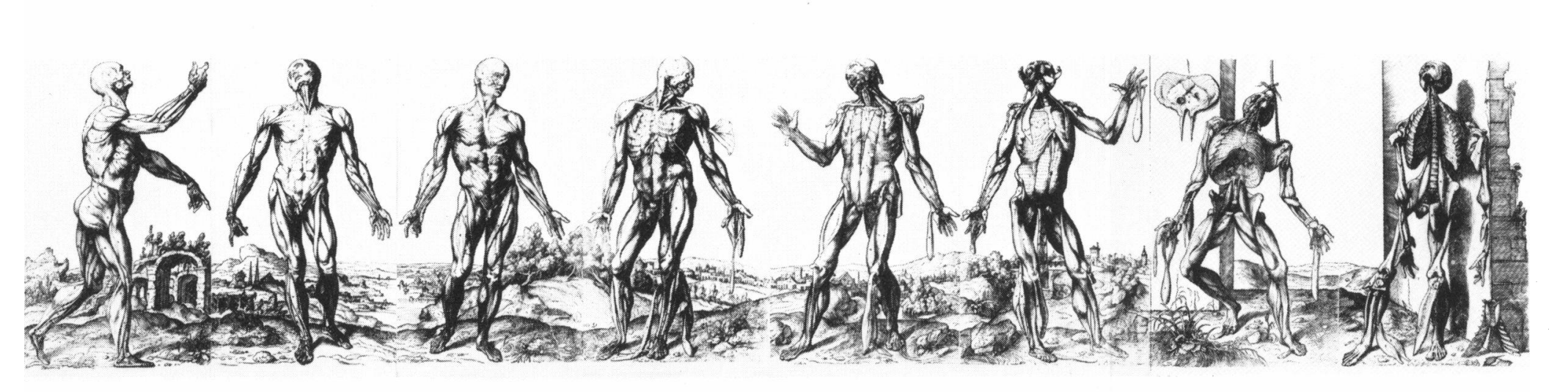

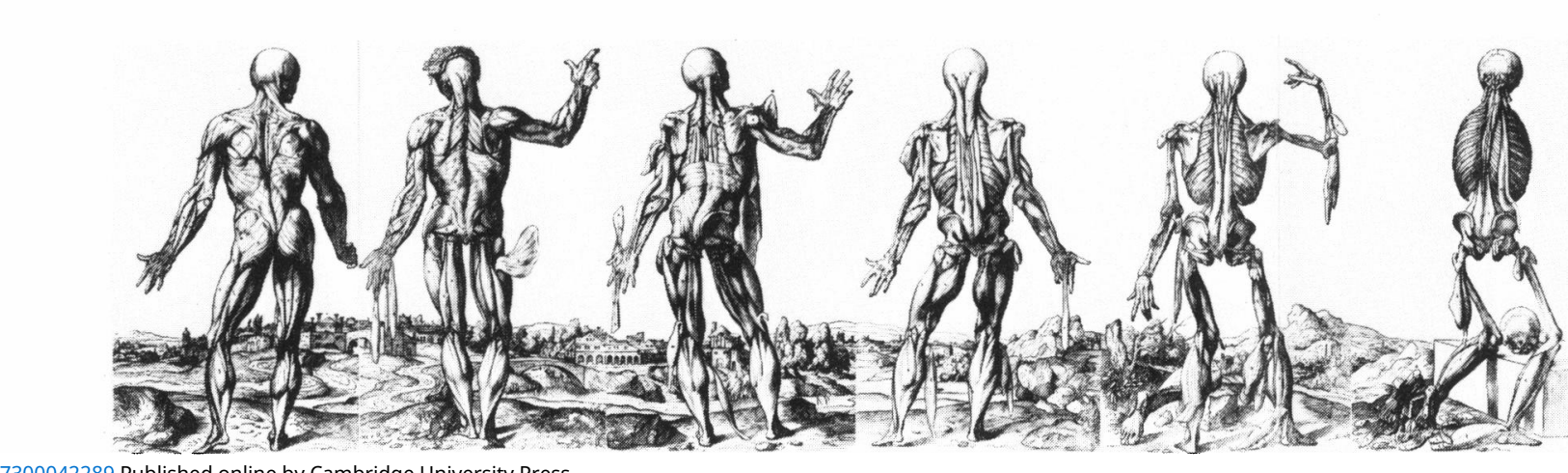




\section{G.S.T. Cavanagh}

inconsistency as evidence that the landscape background was of no importance to Vesalius's grand scheme and that therefore it was not to be expected that there should be agreement in the order. That is not satisfactory in view of what we know of the care which Vesalius lavished on the technical aspects of the production of the book. O'Malley himself gives ample evidence of the pains that were taken to produce a harmonious and well-constructed book. Finally, Martin Kemp, ${ }^{5}$ an art historian who seems to have the best understanding of the artistic aspects of the muscle series, makes the surprising statement that he is unable to detect a connected landscape there at all.

Most of the difficulties recorded by these scholars disappear if a consideration of print-making and book-making technique is applied to the problem. Leaving aside the title-pages, only one drawing has survived which may be part of the original art-work for the anatomical illustrations. This is a red chalk drawing, now in Munich, which corresponds in reverse to Vesalius's second plate of muscles. ${ }^{6}$ Whether or not it is the original from which the wood-engraver worked, we can assume that it is at least representative of the drawings made from the dissections of muscles and that the landscape backgrounds were quite separate, probably in the form of two long drawings which were cut into pieces and allocated as the background to the various figures. The woodcut artist's task then would have been to incorporate two separate drawings, one of a muscle figure, one of a part of a landscape, into a unified composition for each plate.

It is a commonplace of print-making that most woodcut and engraved impressions are in reverse from the drawings on which they are based. It will inevitably be so unless special pains are taken to prevent it, as was the case with Rubens, whose drawings were sometimes redrawn in reverse by a secondary artist before they went to the engraver to ensure that the end result would agree with the original. There is no reason to assume that any such procedure involving an intermediate, reversed drawing was used in the production of the Fabrica, but there is strong support for the belief that many of the Vesalian woodcut illustrations as known to us are in fact reversed images of the original drawings and of the anatomical material they represent. In one instance recorded by $\mathrm{O}^{\prime}$ Malley, ${ }^{7}$ Vesalius's text disagrees with his illustration, confusing right with left, apparently because he was writing with the original drawing before him rather than a proof. Further, the two most acceptable candidates as survivors of the original drawings, the red chalk muscle-man mentioned above and the Crummer drawing of the title-page scene, are in reverse from the published images. ${ }^{8}$

An additional small but significant detail is that where any of the figures in the printed illustrations casts a shadow it falls as though the light source were to the right, a situation which right-handed artists studiously avoid so that they will not have to work in the shadow of their own hand. One would expect the shadows in the original drawings to fall to the right, and in the Munich drawing they do so.

It occurred to me that in the absence of the original layouts, the most conclusive evidence that normal image reversal took place in the muscle series might lie in a

\footnotetext{
'Martin Kemp, 'A drawing for the Fabrica; and some thoughts upon the Vesalius muscle-men', Med. Hist., 1970, 14: 277-288.

6 Ibid.

'O'Malley, op. cit., note 4 above, p. 129.

Ibid., p. 125.
} 


\section{A new view of the Vesalian landscape}

photographic reconstruction of those layouts. The muscle plates were photographed individually, positive prints were made in reverse; that is, with the negatives turned over in the enlarger, and the prints were cut and assembled to form the connected landscapes. The landscapes now appear as a mirror image of the "Cushing" reconstruction referred to above, but the muscle figures progress across them in a logical order following the sequence of the book. Even the balletic rhythm of the series is greatly enhanced by this revision. In particular, the one side-view figure of the fourteen is now made to open the series and to lead into the rest with his dramatic gesture, instead of rather foolishly bringing up the rear.

The result, as seen in the two longer sequences of the plate representing the eight anterior and six posterior muscle figures, is probably as close as we can come to the original plan. It should be noted that this planned order was immediately changed before the printing of the book, when the first frontal figure rather than the side view was chosen to open Book 2. The muscle-men and the landscape are to be regarded as two separate elements which were only brought together on the wood blocks. The text itself was the paramount concern, and the use of the figures to illustrate the text took precedence over the landscape, which lost its integrity in the process. It is now seen reconstructed, presumably for the first time. If this reconstruction is correct it suggests that in the Fabrica artist and anatomist conceived for the illustration of Book 2 a complex and important design which has been largely lost to us because of the mechanics of book production.

\section{SUMMARY}

Of the more than two hundred woodcut illustrations in the Fabrica of Vesalius, the most striking are the fourteen full-page plates of "muscle-men" in the second book. A feature of this series is the use of a detailed landscape as a background for the human figures. It has previously been recognized that a number of parts of this background can be assembled to form a connected panorama and that the landscape cannot be assembled without disturbance of the order of the figures as they appear in the book and as the progress of dissection requires.

The present paper puts forward the suggestion that most of the illustrations to the anatomy of Vesalius were copied directly on to the wood blocks and not traced on to them, so that the resulting published impressions are mirror images of the original drawings. By making a series of photographic negatives from the 1543 edition and printing these in reverse, it has been possible to assemble the muscle figures in two series so that two complete landscapes are formed with the muscle-men appearing on them in the same sequence as in the book itself. The landscapes so produced are believed to recreate the original landscape drawings and the original intention of Vesalius in making the layout for his book. 